\title{
Meaningful Learning and Its Implications for Language Education in Vietnam
}

\begin{abstract}
Bui Phu Hung
Van Hien University

Correspondence concerning this review article should be addressed to Bui Phu Hung, Van Hien University, 665-667-669 Dien Bien Phu, Ward 1, District 3, Ho Chi Minh 700000, Viet Nam.

E-mail: buiphuhung@yahoo.com

This paper attempts to make an argument for meaningful learning as an essential factor in the teaching of English as a foreign language. Meaningful learning rests its theories against cognitive processing. While contemporary literature shows knowledge of language in general is essential for second language use, this research is mainly concerned with ways of improving students' language use. It has proved that meaningful learning facilitates the retention of knowledge as it makes learners organize their knowledge logically. In the classroom, the teacher should offer activities that relate the new input to learners' existing knowledge, for which cognitive engagement is required. In English language teaching, it is important for teachers to know that learner-centeredness should be applied because they are the ones who process knowledge. This paper begins with an overview of different approaches of foreign language teaching, then presents theories in which meaningful learning is grounded and rooted. The discussion of how one's knowledge of a first language is essential for foreign language learning is given prior to giving implications of meaningful learning in the Vietnamese context.
\end{abstract}

Keywords: meaningful learning, English language teaching, cognitive processing, neuroscience, Vietnamese context

\section{Introduction}

English language teaching (ELT) has been influenced by different approaches, including the four main theories: behaviorist, cognitive, humanistic, and socio-cultural theories (Cooper, 2009). Behaviorism places an emphasis on observable behavior in that it operates as an unconscious stimulus-response process. In particular, learners respond to stimuli and disregard the meanings of their utterances. Cognitivism, by contrast, regards learning purely as an active inner mental process in which cognitivists argue that the human mind is essential for information processing. Knowledge is a consequence of how information is received, organized, and memorized by the learner. The central assumption of the humanistic approach is that learning is a personal act used to fulfill the learner's potential. Thus, it focuses on self-motivation and goals as particular issues of interest. The socio-cultural approach, advocated by Vygotsky, distinctively describes learning as a social process in which interactions play a pivotal role in learning and acquiring language (Currie, 2008).

It is obvious that behaviorism rests mainly against the assumption that learning a language should be based on repetition as a response to stimuli. In other words, it does not place an emphasis on the meanings of the target items. However, the other three theories of ELT are based on meaningful learning. At this point, it can be said that meaningful learning is involved in most of the main theories of ELT (Alberto \& Troutman, 2003).

Meaningful learning is a principle of language teaching and learning. In fact, teachers are advised to teach for meaningful learning and learners are advised to systematically and cognitively relate the new input with their existing knowledge so that they can build a cognitive structure (Brown, 2000). Teachers are advised to teach for meaningful learning, where relevant, providing that it engages students emotionally, socially, and cognitively. Thornbury (2002) believes that any teaching activity that fails to engage learners cannot be considered effective. That is, meaningful learning is relatively vital.

This paper aims to clarify the notion of meaningful learning, compared with rote learning, as a recommendation 
to EFL teachers and learners. It consists of three main parts. This current part, as Part 1, introduces the place of meaningful learning in ELT as well as the significance of this principle. Part 2 demonstrates the main concepts and characteristics of meaningful learning compared with rote learning and related studies on meaningful learning. Part 3 makes recommendations on how meaningful learning should be applied in Vietnamese contexts.

\section{Meaningful Learning}

The key scholars of the cognitive approach, Long (2009) and Ellis (2010), are not sure about how relevant the findings on second language acquisition research can be to practicing teachers since the cognitive paradigm has offered little that teachers can use directly in a classroom of English as an additional language. These two scholars argue for a balanced mix of implicit and explicit instruction, with teachers paying attention to students' meaningful learning through the cognitive process. Accordingly, a lesson design where students are expected to use specific conversational strategies, such as the native speaker's corrections, questions, modifications, and requests were proposed and then modified to facilitate the acquisition of grammar in the hope that these communicative strategies could improve learners' awareness of grammatical problems and offer opportunities for self-correction. This cognitive awareness strategy has been thought to increase students' knowledge and retention of the target items.

It has been widely accepted among linguists and language educators that the cognitive process plays a key role in learners' language use, especially for adult language learners. Knowing how the brain tells things apart is a significant question since language presents learners with the problem of discerning between the elements that matter and those that do not. Supporting this process requires an understanding of the processes, elements, and pathways that participate in this process. The findings show that in-depth engagement with the literature from different fields of research, not only neuroscience, can assist language and educational researchers with new insights into the process of learning and new sources of questions that can lead to more research and more developments in foreign language teaching. The key points demonstrate a large number of neurons respond to very simple visual object. Cognitive networks, as a foundation for meaningful learning, are constructed throughout the lifetime of an individual and their disturbed, multi-level structure provides people with sufficient support recognition (Kendrick, 2010).

It is now significant to clarify what meaningful learning is in comparison with rote learning. According to Ausubel (2000), learning can be either rote learning or meaningful learning. They may both assist the learning process with different functions and levels of effectiveness. Rote learning is simple memorization as it leads to "acquiring discrete and relatively isolated entities that can be related to cognitive structure only in an arbitrary and verbatim fashion” (Novak \& Canãs, 2009). This process fails to build a cognitive structure since learners do not make endeavors to integrate new knowledge with relevant existing knowledge in cognitive structures. The learning of new knowledge requires cognitive processes to make sense of new input involving the mental storage of target items in association with existing cognitive structures. Meaningful learning, on the other hand, is "created through some form of representational equivalence between language and mental contexts (Cooper, 2009). During meaningful learning, learners should "seek a way to connect or integrate new concepts or ideas with related ideas in the cognitive structure", which facilitates adding existing knowledge from prior experiences to cognitive structures as well as refine the existing ideas (Novak, 2002). That is to say, meaningful learning is the way of acquiring input by applying prior knowledge to new situations by the construction of a mental model (Mayer \& Moreno, 2003). The process of meaningful learning generally includes selecting the information, organizing the information, activating related prior knowledge and constructing coherence formation by integrating information from different sources. This process reflects the characteristics of constructivist thinking and enables learners to present their thinking in concrete ways and visualize and test the consequences of their reasoning (Jonassen \& Land, 2000).

Novak (2002) made a presentation on concept maps as instruments for representing knowledge visually, which is based on Ausubel's (2000) work. His research garnered a great deal of interest from educators because visual aids are relatively helpful. His study explored how learners' concepts are linked. Ballester (2011) also confirmed the applicability of meaningful learning in education. Accordingly, classroom activities should center on the learners as they are the agents who must learn. The teacher-centered approach is not really effective as learners are passive in the learning process. Secondly, the learner is the one who must construct knowledge; as a result, listening and note taking do not really help the learner absorb a lot of knowledge from the lecturer. It 
is significant to apply experiential learning. That is, experience facilitates effective learning. Also, meaningful learning takes place when learners experience the real world. Any learning activity that does not relate the input to things in real life does not help learners retain the knowledge for a relatively long period. If the classroom activity does not engage the learners cognitively, that classroom fails to be considered effective as retention does not take place.

Continuing the discussion on meaningful learning, Ausubel (2000) provides a specific model with three main phases: using an advanced organizer, presenting the learning tasks or materials, and strengthening cognitive organization. In the first phase, it is important that the teacher clarify the objectives of the lesson, present the lesson, and relate the learner's existing knowledge to the new input. Secondly, task-based activities should be utilized to cognitively engage the learner. It is also pivotal to note that meaningful learning is for explicit instruction so that learners can logically organize their knowledge, examples, and new discoveries. Finally, learners can advance their active learning by promoting mental processes.

Previously, there were some psycholinguists who believed that some language items were meaningless and so-called "functional class" (Chomsky, 1981). However, modern schools of linguistics believe that all language items have meanings. Grammatical items, such as tense and articles, are also found to have meanings and it is possible to use symbolic images to present the meanings of language items (Evans, 2007; Nguyen Thu Huong, 2005; Langacker, 2008). Schnotz (2005) also believes that learners may retain language items longer and are then able to use them when they learn meanings rather than forms of the target items.

A discussion of a principle or practice would be insufficient without a review of related studies. Hung (2017) did a quasi-experimental study applying meaningful learning and rote-learning to teaching English prepositions in Vietnam. Before the study, the participants received a pre-questionnaire and a pre-test to diagnose their knowledge of the meanings of prepositions and investigate what types of the instruction they had previously received. After the treatment, the participants did the post-test and answer a post-questionnaire. The experimental evidence revealed that the participants who learn meaningfully outperformed those who did rote learning. They also responded that they preferred meaningful learning to rote learning.

Valadares (2013) carried out a study using concept maps as a tool of meaningful learning to relate different concepts in a hierarchical diagram so that learners could conceptually organize both their prior and new knowledge bodies. His conclusion is that concept maps can be used to facilitate meaningful learning. However, it is essential to know the perspectives that allow for the use of these maps properly. Otherwise, the teacher has to face the risk that memory learning (rote learning) would be stimulated. Also motivated by meaningful learning, Song (2013) conducted his study on assisting students' meaningful learning (ML) of English prepositions. The study included two groups: an experimental group (ML-inspired treatment) and a control group (rote learning). The findings illustrated that the experimental group outperformed the control group in the post-test whereas their mean scores were comparable in the pre-test. Haywood, Walker, O'Toole, Hewitson, Pugh, and Sundaram (2009) reported their research on engaging young people in meaningful learning and finally made several conclusions and implications. First, it was hard to engage young college students in meaningful learning as they had their own learning strategies gained from their previous experiences and education as well as other barriers. However, the findings showed that meaningful learning helped longer-term retention of knowledge.

It is crucial to know that meaningful learning is in line with learners' cognitive engagement (Hung, Truong \& Nguyen 2018; Hung, Vien \& Vu 2018). That is, in the field of language education, it is for learning a language, not language acquisition because language learning requires a cognitive processes of language input, but language acquisition takes place in the environment in which the target language is used. Nevertheless, learning and acquisition processes are in a dichotomous continuum in adults. That is, adults first learn a language, which later enables them to use it during communicative activities and these activities help modify their language naturally (Gass \& Selinder, 2008). The abovementioned review shows that meaningful learning was essential for language learning and development.

\section{How to Achieve Meaningful Learning in the Vietnamese Context}

It is important for EFL (English as a foreign language) teachers to facilitate meaningful learning, and language learners should apply meaningful learning in acquiring the target items. It is also crucial to note that meaningful 
learning is a principle of ELT. In other words, it is advised by experts in English language teaching and learning.

Regarding the Vietnamese context, where rote learning has been long applied (Canh, 2011, 2014), meaningful learning should be considered as a facilitative tool. In secondary and the tertiary levels of education, learners have existing knowledge from prior education as Vietnamese education is usage-based. Existing knowledge is a critical element for achieving meaningful learning. However, it may be hard to apply this principle in primary schools since Vietnamese parents are widely believed to have lower education than their peers in many other countries. Vietnamese education is not free of charge but compulsory at present. How can meaningful learning be applied in primary schools when many children do not receive sufficient knowledge to prepare for primary education?

The government should bear in mind appropriate policies for education in order to facilitate adult education. In other words, education should be free to minorities and people who cannot afford tuition fees. This may be time consuming and costly, but it should be done as soon as possible.

EFL teachers in places where locals are assumed to have lower levels of education need to provide students with some basic relevant knowledge prior to performing an intended lesson. For instance, before performing a listening activity, the teacher can let his or her students discuss related issues without expecting them to give good answers as unrealistic expectations can destroy the class atmosphere. The teacher should be the one who makes additions to the students' answers in order to prepare the students for the main task in the hope that the students can make sense of the listening passages without undue effort. In English language teaching, before giving the target input, teachers can offer studies opportunities to review the knowledge that they have already learned. EFL teachers can also offer pre-teaching tasks to prepare students for the cognitive processing of the target input (Hung \& Van, 2018).

Last but not least, it is important to carry out studies on the applications of meaningful learning in Vietnamese contexts, such as in mountainous, rural, and urban areas to figure out the extent to which this principle has been applied and understood by EFL teachers in Vietnam. The findings should be used to modify further in-service training courses for EFL teachers.

With a limited amount of research interested in exploring the applications of meaningful learning in English language teaching, especially in the Vietnamese context, it is hard for this paper to have a more profound discussion and provision of the empirical results from previous studies. However, it is obvious that meaningful learning should be applied to education in general and ELT in particular. Educators, policy makers, and parents should all be aware of this principle and take responsibility of facilitating its applications.

\section{References}

Alberto, P. A. \& Troutman, A. C. (2003). Applied behavior analysis for teachers (6th ed.). Upper Saddle River, NJ: Merrill Prentice Hall.

Ausubel, D. P. (2000). The acquisition and retention of knowledge: A cognitive view. Boston, MA: Kluwer Academic Publishers.

Brown, H. D. (2000). Principles of language teaching and learning (4th ed.). New York, NY: Pearson Education.

Canh, L. V. (2011). Form-focused instruction: A case study of Vietnamese teachers' beliefs and practices (Unpublished $\mathrm{PhD}$ thesis in Applied Linguistics). University of Waikato, Hamilton, Waikato, New Zealand.

Canh, L. V. (2014). Great expectations: The TESOL practicum as a professional learning experience. TESOL Journal, 5(2), 199-224. doi: https://doi.org/10.1002/tesj.103

Cooper, S. (2009). Theories of learning in educational psychology. Jack Mezirow: Transformational Learning Theory. Retrieved from: http://www. lifecircles-inc. com/Learningtheories/humanist/mezirow. html

Currie, Q. T. (2008). Animation as reality: Factors impacting cognitive load in studio-based E-learning (Unpublished Doctoral dissertation). Capella University, Minneapolis, MN.

Evans, V. (2007). A glossary of cognitive linguistics. Salt Lake City, UT: University of Utah Press.

Gass, S. M., \& Selinder, L. (2008). Second language acquisition: An introductory course (3rd ed.). New York, NY \& London, UK: Routledge. 


\section{BUI PHU HUNG}

Haywood, N., Walker, S., O’Toole, G., Hewitson, C., Pugh, E., \& Sundaram, P. (2009). Engaging all young people in meaningful learning after 16: A review. Manchester, UK: Equality and Human Right Commission.

Hung, B. P. (2017). Vietnamese students learning English prepositions. GEMA Online Journal of Language Studies, 17(4), 146158. doi: http://doi.org/10.17576/gema-2017-1704-10

Hung, B. P., Truong, V., \& Nguyen, N. V. (2018). Students' responses to CL-based teaching of English prepositions. Eurasian Journal of Educational Research, 73, 41-58.

Hung, B. P., \& Van, L. (2018). Depciting and outlining as pre-writing strategies: Experimental results and learners' opinions. International Journal of Instruction, 11(2), 451-464. doi: 10.12973/iji.2018.11231a

Hung, B. P., Vien, T., \& Vu, N. N. (2018). Applying cognitive linguistics to teaching English prepositions: A quasi-experimental study. International Journal of Instruction, 11(3), 327-346. doi: https://doi.org/10.12973/ iji.2018.11323a

Huong, N. T. (2005). Vietnamese students mastering English articles (Unpublished Doctoral thesis). University of Groningen, Groningen, the Netherlands. Retrieved from https://www.rug.nl/research/portal/files/2925155/ thesis.pdf

Jonassen, D., \& Land, S. (2000). Theoretical foundations of learning environments. Hillsdale, NJ: Erlbaum.

Langacker, R. W. (2008). Cognitive grammar as a basis for language instruction. In P. Robinson \& N. C. Ellis (Eds.), Handbook of cognitive linguistics and second language acquisition (pp. 66-68). New York, NY: Routledge.

Mayer, R. E., \& Moreno, R. (2003). Nine ways to reduce cognitive load in multimedia learning. Educational Psychologist, 38(1), 43-52.

Novak, J. D. (2002). Meaningful learning: The essential factor for conceptual change in limited or appropriate propositional hierarchies leading to empowerment of learners. Science Education, 86(4), 548-571. doi: https:// doi.org/10.1002/sce.10032

Schnotz, W. (2005). An integrated model of text and picture comprehension. In R. E. Mayer (Ed.), Cambridge Handbook of Multimedia Learning (pp. 49-69). Cambridge, UK: Cambridge University Press.

Song, X. (2013). A cognitive linguistic approach to teaching English prepositions (Unpublished Doctoral dissertation). University of Koblenz-Landau, Koblenz, Germany.

Thornbury, S. (2002). How to teach grammar (4th ed.). Essex, UK: Pearson Education.

Valadares, J. (2013). Concept maps and the meaningful learning of science. Journal for Educators, Teachers and Trainers, 4, 164-179. Retrieved from http://jett.labosfor.com/index.php/jett 